Published citation:

Poletz, L., Encarnação, P., Adams, K., \& Cook, A. (2010). Robot Skills and Cognitive Performance of Preschool Children. Technology and Disability. 22, 117-126.

\title{
Robot Skills and Cognitive Performance of Preschool Children
}

\author{
Linda Poletz $^{1}$, Pedro Encarnação ${ }^{3 *}$, Kim Adams ${ }^{1,2}$, and Al Cook ${ }^{1}$ \\ ${ }^{1}$ Faculty of Rehabilitation Medicine, University of Alberta \\ ${ }^{2}$ Glenrose Rehabilitation Hospital, Edmonton, Alberta, Canada \\ ${ }^{3}$ Faculty of Engineering, Catholic University of Portugal, Sintra, Portugal
}

\begin{abstract}
Several studies have demonstrated the potential of robots as assistive tools for play activities. Through the use of robots, children with motor impairments may be able to manipulate objects and engage in play activities as their typically developing peers, thus having the same opportunities to learn cognitive, social, motor and linguistic skills. Robot use can also provide a proxy measure of disabled children's cognitive abilities by comparing their performance with that of typically developing children. This paper reports a study with eighteen typically developing children aged three, four and five years to assess at which ages the cognitive concepts of causality, negation, binary logic, and sequencing are demonstrated during Lego robot use.
\end{abstract}

\section{KEYWORDS}

Assistive robotics; Play; Cognitive development assessment

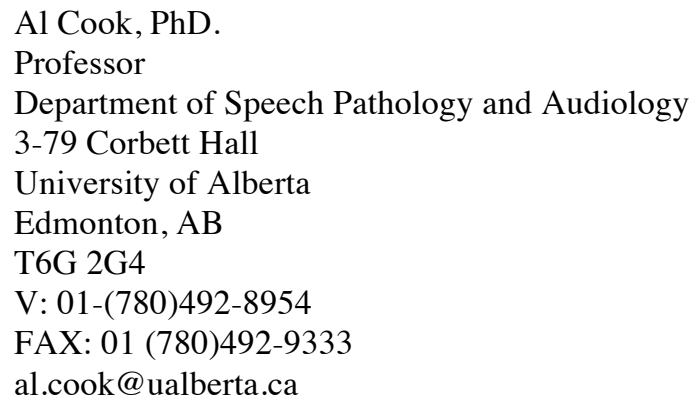

\footnotetext{
* The work of Pedro Encarnação was done during a sabbatical at the University of Alberta and at the Glenrose Rehabilitation Hospital, and was supported in part by a FCT Fellowship.
} 


\section{BACKGROUND}

During typical development, play activities provide an opportunity for children to learn cognitive, social, motor and linguistic skills through the manipulation of objects. Children who have movement disorders may have difficulty manipulating objects, thereby compromising the quality of play and learning of skills [15]. It can be difficult to ascertain the developmental level of children with motor disorders since many standardized tests are difficult to use and interpret with this population due to the requirement to use speech or fine motor control, or both (children with motor disorders frequently also have speech disorders). Consequently these children may be perceived as being more developmentally delayed than they actually are. Robots provide an opportunity for them to choose how to interact with their environment, to exert some control over the activity, and to manipulate three-dimensional objects. Play-based manipulation using robot tasks can also provide a method for children to demonstrate their understanding of cognitive concepts.

Robots have been used successfully in a number of studies to allow children with disabilities to participate in play and engage in school-based activities. Pre-school and elementary school children with moderate to severe physical impairments, and cognitive delays participated in manipulative tasks using a robot [11]. Children with cerebral palsy (CP) used an adapted Manus arm for various pick and place academic activities [13, 14]. The Handy 1 Robot, originally designed as a feeding aid, was adapted for use in a drawing task to allow children to complete assignments with minimal assistance in class alongside peers [19]. A specially designed robot for access to science lab activities was trialed with seven students aged 9 to 11 years who had physical disabilities [10]. Access to the science and art curricula for students, aged 10 to 18 years, who had arthrogryposis, muscular dystrophy, and CP was evaluated with a multipurpose workstation called the ArlynArm [7]. Robot use allowed control over component actions of complex sequences to complete academic science tasks [16]. Children with disabilities used a robot workstation based on the low-cost commercial SCARA robot for stacking and knocking down toy bricks, sorting articles, and playing the Tower of Hanoi game [9]. In the PlayROB project [12], a dedicated robot system which supports children with severe physical impairments in their interaction with standard toys was developed. A first set of trials was conducted with three able-bodied children (between 5 and 7 yrs old) and three disabled children (between 9 and 11 yrs old). The majority of children were able to use the robot independently and appeared to enjoy the activity. Upgraded versions of the system were then used in a multi-centre longitudinal study involving children with and without disabilities. Results showed that children were able to progressively master the robot, playing autonomously with high concentration and enjoyment, even for long periods of time. Additionally, improvement on child's spatial perception was reported [12]. There is an ongoing Playbot project, aimed at building a robotic system for assistive play using vision as the primary sensor [1, 21]. Another project, IROMEC, is investigating how robotic toys can become social mediators and provide opportunities for learning and enjoyment and focuses on the importance of play in child development and the role that robotics can play in enabling play by children who have disabilities [2]. The IROMEC project team has developed a set of play scenarios that serve to set the context for users to be involved in the design process of appropriate robotics activities and hardware. They have identified four types of play: sensory motor play, symbolic play, constructive play and games with rules [18]. A flexible modular mobile robot has been developed by the IROMEC project to 
accommodate multiple users and play scenarios [17]. The robot can be adapted to play scenarios with three populations of children with disabilities (autism spectrum disorder, intellectual disabilities and severe motor impairment) in three clusters of activities (imitation, actions and coordination, and symbolic play).

Most of the previous robot studies carried out with children who have disabilities have focused on compensating for the physical limitations of the child through augmented manipulation. Manipulating an object via a robot is a different task than directly manipulating the object with one's hand. It is important to understand the cognitive demands that are placed on children who are using robots for functional manipulation.

Previous studies have reported the use of robots to demonstrate previously unmeasured cognitive skills, even in very young children. Disabled and typicallydeveloping children greater than 8 months in age demonstrated the cognitive skill of tool use by using a robot to bring an object closer to them [3]. A multistep structured play task to uncover a hidden toy was carried out by children aged 6-14 who had severe cerebral palsy [4]. The children performed a sequence of tasks by activating one or more switches. Even though the majority of the participants could not be evaluated through standard cognitive measures, teachers noticed differences in overall responsiveness, amount of vocalization and interest (i.e., increased attention to tasks) for children who used the robotic arm,. Overall, these studies demonstrate that using the robots children can reveal skills that had not been previously measured.

In order to gain a sense of the cognitive performance level of children with disabilities using robots, performance of typically developing children at varying developmental ages can be used as an informal measure. However, there have not been many studies showing children's skills in robot use at different ages. Children aged three to seven using a Robotix ${ }^{\mathrm{TM}}$ robot construction kit demonstrated five cognitive skills: cause and effect relations, spatial relations, binary logic, the coordination of multiple variables, and reflectivity [8]. The specific skills demonstrated by the children in each of these areas varied with age, i.e., older children demonstrated greater understanding of each concept than did younger children. Stanger and Cook [20] studied typically developing children one to three years of age using a Hero 2000 robot in a series of increasingly cognitively complex tasks. Two questions were asked in a five step protocol. First, does the child use the robot to do something interesting for him (cause and effect)? Second, can the child use a sequence of robot control commands to carry out a task? As in Forman's study, older children demonstrated greater understanding of each concept than did younger children

While Forman [8] and Stanger and Cook [20] are the only studies of which we are aware that specifically looked at typically developing young children's understanding of robotic skills, the developmental sequence of skills reported in those studies is similar to those described by standard measures of typical cognitive development [22], and in classification schemes such as the World Health Organization, International Classification of Functioning for Children and Youth (ICF-CY) [23]. The ICF-CY includes developmental considerations for children in a number of areas. The categories of Mental Functions (included in Body Functions) and Learning and Applying Knowledge (included in Activities and Participation) are particularly relevant to the current study. Classifications that are related to the cognitive functions and use of robots include the mental functions of orientation to objects, motivation, attention, organization of psychomotor functions (including goal directed sequences), and basic cognitive functions (e.g. "acquisition of knowledge about objects, events and 
experiences; and the organization and application of that knowledge in tasks requiring mental activity" [23, classification b163]). Activity and participation classifications in the ICF-CY that relate to work with children and robots include learning through simple actions with single and/or multiple objects, acquiring basic concepts, making decisions among choices and "carrying out simple or complex and coordinated actions as components of multiple, integrated and complex tasks in sequence or simultaneously" [23, classification d220].

With respect to studies showing the robot skills of children with disabilities, we are aware of only one. In a study with children with disabilities, ten children were observed during unstructured robotic play activities to determine if they demonstrated certain cognitive skills. An observation checklist was used that was based on the cognitive skills observed by Forman [8]: Causality, Negation, Binary Logic, Spatial concepts in multiple dimension (i.e., making sequential movements in multiple dimensions), Symbolic Play, and Problem solving) [6]. Note that negation was studied by Forman under cause and effect relations. It was found that even the children who were not testable with standardized tests were able to demonstrate skills with the robot up to the level of sequencing. The children with the most severe cognitive disabilities understood causality but not negation or binary relations. The sequence of skill understanding with increasing age (causality, then negation, then binary relations) appeared to apply to these children as well. However, in this case the progression in skills was related to their cognitive or developmental level, and not necessarily chronological age. In order to use the demonstration of robot skills as a proxy measure of cognitive level, it is necessary to examine more closely at what ages the robot skills emerge in typically developing children.

The purpose of the current study was to confirm the ages at which four cognitive concepts (causality, negation, binary logic, and sequencing) are demonstrated during robot use by typically developing children aged three, four, and five years using a Lego robot controlled with multiple switches. The choice of these cognitive tasks was based on two considerations. First, three of the tasks causality, negation and binary logic- were shown by Forman to be developmentally related, i.e. older children demonstrated greater understanding of each concept than did younger children. He also showed that these three skills formed a developmental sequence with causality preceding negation and negation preceding binary relations in terms of the ages at which children understood each task, both through demonstrated performance and in answers to subsequent questions regarding that performance. The other skills identified by Forman - the coordination of multiple variables, and reflectivity - were characteristic of older children. This is inline with ICF-CY that includes these cognitive skills in "Highlevel cognitive functions" [23, classification b164]. Secondly, since our focus was on children for whom cognitive assessment was difficult using standardized measures, we focused on the three to five year old age range, which corresponds to the ages at which Forman saw typically developing children demonstrating the lower-level skills. Due to the importance of sequencing in our previous work with children who have disabilities $[4,6]$ and young children without disabilities [20], we included a sequencing task as well.

In both the study by Forman [8] and that by Stanger and Cook [20], the developmental progression by age was based on relatively unstructured play activities and observation of the children. We undertook the current study to provide a more controlled and objective look at these skills. 


\section{METHODOLOGY}

\begin{tabular}{|l|l|l|}
\hline Age Range & Male & Female \\
\hline 3 years (35-38 mo.) & 2 & 3 \\
\hline 4 years (46-52 mo.) & 5 & 3 \\
\hline 5 years (62-63 mo.) & 2 & 3 \\
\hline
\end{tabular}

Table 1: Participant information.

Eighteen typically developing children were included in the study with ages three, four and five years \pm 3 months (Table 1). Informed consent was obtained from the parents for each child in accordance with approved ethics guidelines. Parents were asked to complete the Ages and Stages Questionnaire to ensure that the child was functioning within the appropriate developmental level.

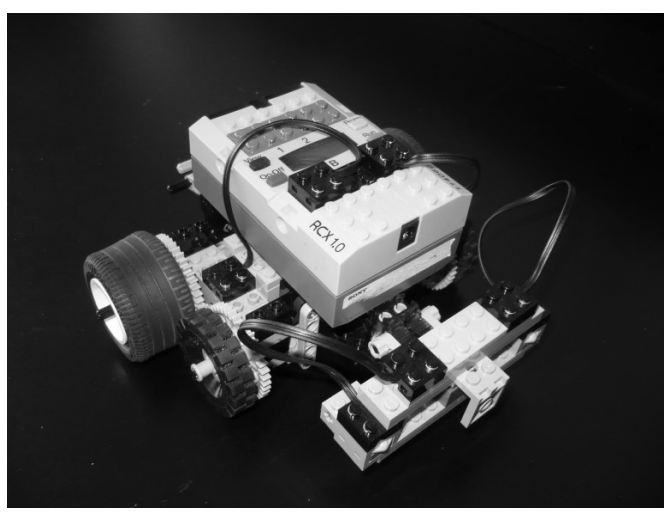

Figure 1: Lego Roverbot robot.

The children used a truck-like Lego roverbot (Figure 1) to carry out three tasks which tested the aforementioned cognitive skills. Task 1 (causality) required the child to press and hold a switch until the roverbot knocked over a stack of blocks (Figure 2). In Task 2 (negation) the child was asked to help build the stack of blocks. They used the same switch as for Task 1, but they were required to stop the roverbot (i.e., release the switch) beside a pile of blocks to allow the investigator to load them onto the roverbot. Then they were required to stop at the original stacked blocks location where the investigator unloaded the blocks (Figure 3). The third task involved two stacks of blocks located to the left and right of the original stack with the roverbot placed between them facing away from the child (Figure 4). The participant was asked to choose a pile (by pointing at it) and then use the roverbot to knock it down. To accomplish that, the child had to use the appropriate one of two additional switches to turn the roverbot 90 degrees left or right (Task 3A - binary logic), and then use the original forward switch to drive the roverbot to knock over the blocks (Task 3B - sequencing of two actions). At the end of the session, the children were asked to explain what the switches did in order to assess their understanding of the task.

The children used the roverbot at their day care setting or at their home, for two 20 minute sessions spaced approximately seven days apart. All of the tasks were performed at both sessions. The number of trials attempted by each child was dependent on how quickly they understood. Each session was videotaped for analysis. The parents were asked to fill out a technology survey questionnaire to assess the child's previous familiarity with on/off switches and multi-button remote controls. Frequency of use (1 - Never, 2 - Weekly, or 3 - Daily) and how children mastered those controls (1 - Low skill (trial and error), 2 Medium skill, or 3 - High skill (mastered)) were assessed.

\footnotetext{
${ }^{\dagger}$ http://www.agesandstages.com/index.html
} 

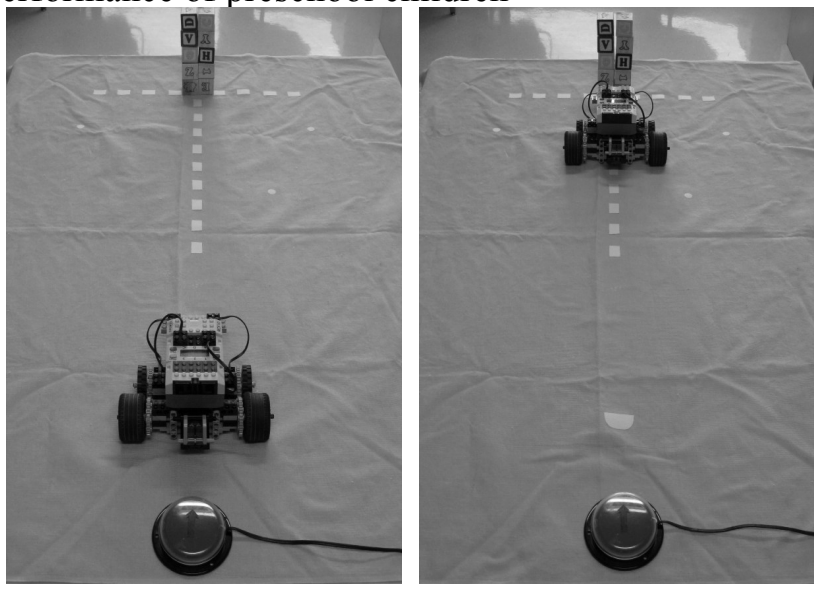

Figure 2: Task 1 - Causality: Press and hold a switch until the roverbot knocked over a stack of blocks.
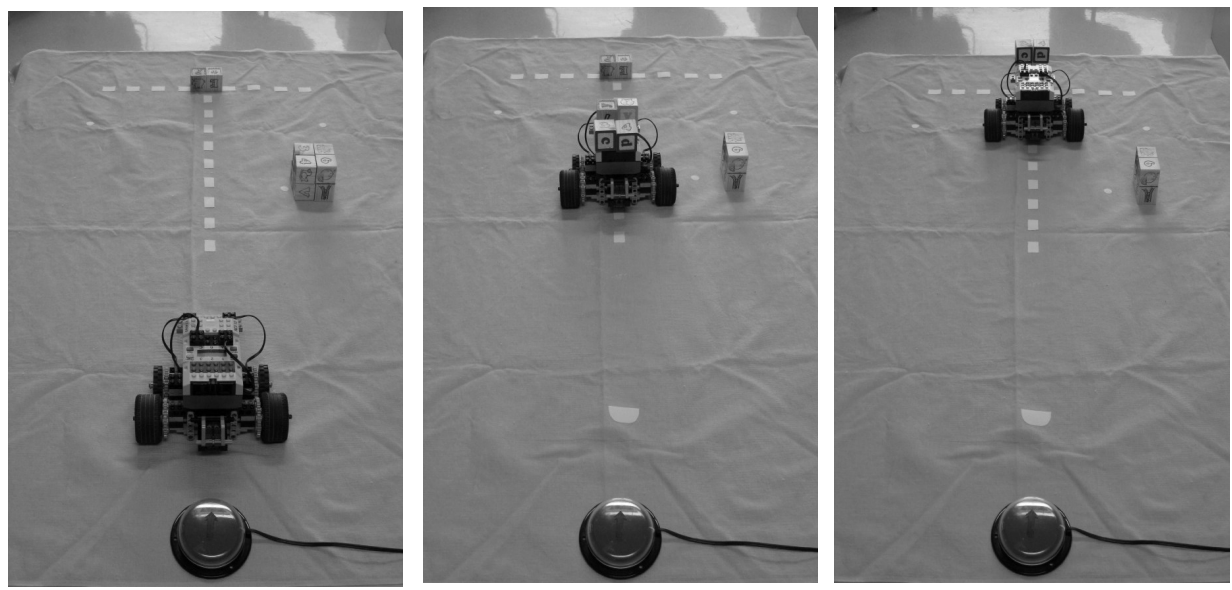

Figure 3: Task 2 - Negation: Move and stop (by releasing the switch) the roverbot beside a pile of blocks to allow the investigator to load them onto the roverbot, and then move and stop the robot at the original stacked blocks location where the investigator unloaded the blocks.
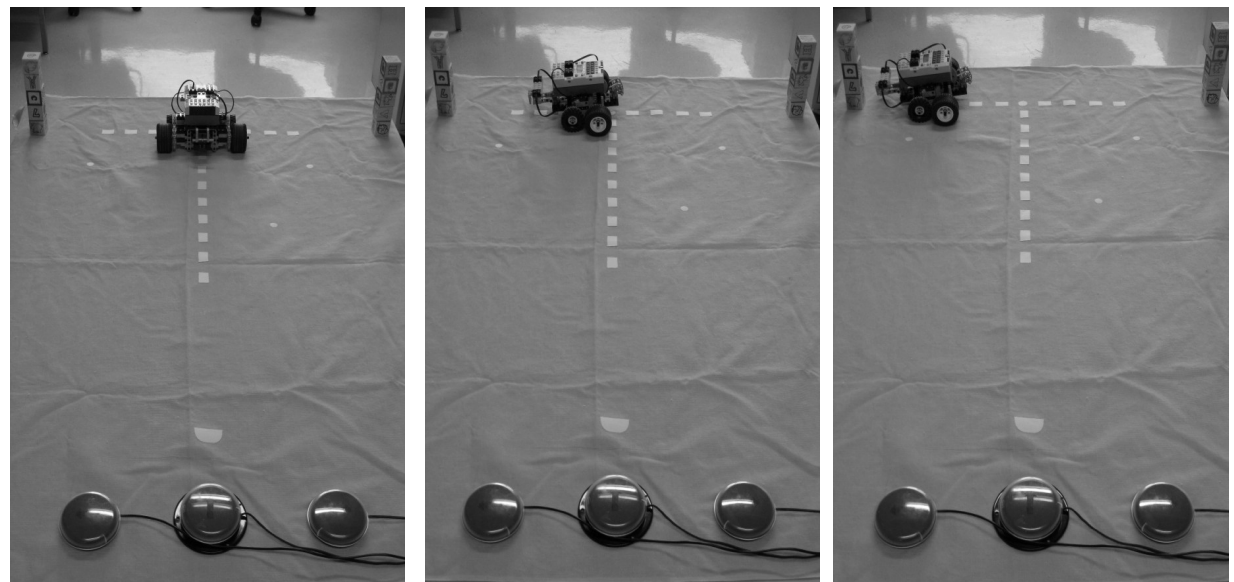

Figure 4: Task 3A-Binary Logic and Task 3B-Sequencing: Use the appropriate one of two additional switches to turn the roverbot 90 degrees left or right (Task $3 \mathrm{~A}$ - binary logic), and then use the original forward switch to drive the roverbot to knock over the blocks (Task $3 B$ sequencing of two actions) 


\section{RESULTS}

The results for the three tasks are summarized in Table 2. Table 3 shows the results of the Welch's t test $(p<0.05)$ statistical analysis performed to test the relationship between performance of each task and age level. In all statistical tests it was assumed that the data available for each age group constituted random independent samples of a normally distributed population. Variances of each age group population were assumed to be different.

\begin{tabular}{|c|c|c|c|c|c|c|c|c|c|c|c|c|c|c|c|c|c|c|}
\hline Participant \# & 8 & 12 & 9 & 16 & 7 & 6 & 14 & 10 & 17 & 3 & 15 & 5 & 13 & 20 & 11 & 4 & 18 & 19 \\
\hline Age (months) & 35 & 35 & 36 & 38 & 38 & 46 & 47 & 47 & 48 & 49 & 49 & 51 & 52 & 62 & 63 & 63 & 63 & 63 \\
\hline Gender & $\mathrm{M}$ & $\mathrm{M}$ & $\mathrm{F}$ & $\mathrm{F}$ & $\mathrm{M}$ & $\mathrm{F}$ & $\mathrm{M}$ & $\mathrm{M}$ & $\mathrm{M}$ & $\mathrm{F}$ & $\mathrm{F}$ & $\mathrm{M}$ & $\mathrm{M}$ & $\mathrm{M}$ & $\mathrm{F}$ & $\mathrm{F}$ & $\mathrm{M}$ & $\mathrm{F}$ \\
\hline \multicolumn{19}{|l|}{ TASK 1 - CAUSALITY } \\
\hline $\begin{array}{l}\text { \# times knocked over } \\
\text { blocks / \# of trials }\end{array}$ & $3 / 3$ & $4 / 4$ & $2 / 2$ & $4 / 4$ & $4 / 4$ & $4 / 4$ & $5 / 5$ & $4 / 4$ & $4 / 4$ & $4 / 4$ & $4 / 4$ & $4 / 4$ & $4 / 4$ & $4 / 4$ & $4 / 4$ & $4 / 4$ & $4 / 4$ & $4 / 4$ \\
\hline $\begin{array}{l}\text { Average \# of hits required } \\
\text { for task }\end{array}$ & 1.3 & 1.0 & 1.0 & 11.8 & 1.5 & 1.8 & 1.0 & 1.0 & 1.8 & 1.0 & 1.8 & 1.3 & 1.3 & 1.0 & 1.0 & 1.0 & 1.8 & 1.0 \\
\hline \multicolumn{19}{|l|}{ TASK 2 - NEGATION } \\
\hline \# times stopped / \# of trials & $7 / 10$ & $0 / 6$ & $10 / 14$ & $4 / 12$ & $8 / 8$ & $8 / 8$ & $7 / 12$ & $10 / 10$ & $14 / 16$ & $8 / 8$ & $8 / 8$ & $8 / 8$ & $10 / 10$ & $8 / 8$ & $8 / 8$ & $11 / 11$ & $8 / 8$ & $8 / 8$ \\
\hline $\begin{array}{l}\text { Average \# of hits required } \\
\text { for task }\end{array}$ & 1.4 & $\mathrm{n} / \mathrm{a}$ & 1.6 & 6 & 1.5 & 1.8 & 1.4 & 1.7 & 1.4 & 1.3 & 1.5 & 1.1 & 3 & 1.4 & 1.1 & 1.6 & 1.3 & 1.6 \\
\hline \multicolumn{19}{|l|}{ TASK 3A - BINARY CHOICE } \\
\hline $\begin{array}{l}\text { \# times turn appropriately / } \\
\text { \# of trials }\end{array}$ & $7 / 11$ & $7 / 13$ & $8 / 13$ & $7 / 15$ & $10 / 10$ & $8 / 8$ & $9 / 14$ & $12 / 12$ & $8 / 13$ & $9 / 9$ & $7 / 10$ & $12 / 12$ & $7 / 9$ & $8 / 8$ & $9 / 9$ & $9 / 9$ & $9 / 9$ & $8 / 8$ \\
\hline \multicolumn{19}{|l|}{ TASK 3B - SEQUENCING } \\
\hline $\begin{array}{l}\text { \# times knocked over } \\
\text { desired stack of blocks / \# } \\
\text { of opportunities }\end{array}$ & $3 / 11$ & $0 / 13$ & $1 / 12$ & $0 / 15$ & $0 / 10$ & $0 / 8$ & $3 / 15$ & $8 / 12$ & $8 / 13$ & $8 / 9$ & $5 / 10$ & $11 / 12$ & $6 / 10$ & $8 / 8$ & $7 / 9$ & $8 / 9$ & $8 / 9$ & $8 / 8$ \\
\hline \multicolumn{19}{|c|}{ LEARNING PROCESS FOR TASK 3} \\
\hline $\begin{array}{l}\# \text { of trials before success - } \\
\text { Session } 1\end{array}$ & 2 & $\mathrm{n} / \mathrm{a}$ & $\mathrm{n} / \mathrm{a}$ & $\mathrm{n} / \mathrm{a}$ & $\mathrm{n} / \mathrm{a}$ & $\mathrm{n} / \mathrm{a}$ & $\mathrm{n} / \mathrm{a}$ & 1 & 2 & 1 & $n / a$ & 0 & 0 & 0 & 2 & 1 & 0 & 0 \\
\hline $\begin{array}{l}\text { \# of trials before success - } \\
\text { Session } 2\end{array}$ & 0 & $\mathrm{n} / \mathrm{a}$ & 2 & $\mathrm{n} / \mathrm{a}$ & n/a & $\mathrm{n} / \mathrm{a}$ & 1 & 0 & 0 & 0 & 0 & 0 & 1 & 0 & 0 & 0 & 1 & 0 \\
\hline
\end{tabular}

Table 2: Summary table of the study results

\begin{tabular}{|c|c|c|}
\hline $\begin{array}{c}\text { Welch's tests p } \\
\text { values }\end{array}$ & $\begin{array}{c}4 \text { yrs old mean } \\
\text { success rate } \\
> \\
3 \text { yrs old mean } \\
\text { success rate }\end{array}$ & $\begin{array}{c}5 \text { yrs old mean } \\
\text { success rate } \\
> \\
4 \text { yrs old mean } \\
\text { success rate }\end{array}$ \\
\hline Task 2 - Negation & 0.044 & 0.12 \\
\hline $\begin{array}{l}\text { Task 3A - Binary } \\
\text { Logic }\end{array}$ & 0.063 & 0.019 \\
\hline $\begin{array}{l}\text { Task 3B - } \\
\text { Sequencing }\end{array}$ & 0.002 & 0.007 \\
\hline
\end{tabular}

Table 3: Pairwise comparison between mean success rates in different age groups - Welch's tests $p$ values. 
All of the children successfully carried out the first task on all trials. In the second task, only one of the youngest participants did not stop on any trial. The others stopped the robot on at least some of the trials. After having the task explained in more detail their performance improved. The average number of successes in Task 2 for the four year olds was significantly greater than for the three year olds (Welch's test, $\mathrm{p}=0.044$ ). The five year olds succeeded in all trials and their average number of successes was not significantly greater than for the four years old (Welch's test, $p=0.120$ ). For Task 3A turning the wrong way was recorded as unsuccessful. Task 3B was recorded as successful if the child knocked over the blocks, even if the child used a different strategy than "turn first then go forward" with only two switch activations. Comparison of the average number of successes between the four and five years old groups and between the three and four year olds revealed that the five year olds performed significantly better in Task 3A than the four year olds (Welch's test, $p=0.019$ ), and that the four year olds performed better than the three year olds, although the latter was not significant (Welch's test, $p=0.063$ ). In Task $3 \mathrm{~B}$, the average number of successes for the five year olds was significantly greater than for the four year olds (Welch's test, $\mathrm{p}=0.007$ ), and this in turn was significantly greater than the average number of successes for the three year olds (Welch's test, $\mathrm{p}=0.002$ ).

\begin{tabular}{|l|c|c|c|}
\hline \multicolumn{1}{|c|}{ Question } & \multicolumn{2}{c|}{$\%$ of incorrect answers } \\
\cline { 2 - 4 } & 3 yrs & 4 yrs & 5 yrs \\
\hline "When this switch [F] is touched, where does the truck go?" & 40 & 19 & 0 \\
\hline "If the truck is turned [90 degrees to the left] and I touch this & 43 & 53 & 0 \\
switch [F], where will the truck go?" & & & \\
\hline "If the truck is turned toward you [facing the child] and I touch this & 33 & 30 & 0 \\
switch [F], where will the truck go?" & & & \\
\hline "When this switch [<--] is touched, where does the truck go?" & 70 & 57 & 20 \\
\hline "When this switch [-->] is touched, where does the truck go?" & 70 & 37 & 20 \\
\hline "If the wire to the switch is cut and I touch this switch, what will & 100 & 43 & 11 \\
the truck do?" & & & \\
\hline
\end{tabular}

Table 4: Percentage of incorrect answers to the questions about the functions of the switches.

The percentage of incorrect responses to the questions regarding the function of the switches are summarized in Table 4. Children aged three had more difficulty understanding the function of the Forward switch when the robot was facing the stack of blocks than the four year olds $(40 \%$ of the three year olds gave wrong answers whereas only about $20 \%$ of the four year olds did). Three and four year old participants had problems in predicting where the robot would move if the Forward switch was hit when the robot was turned 90 degrees 
to the left (approximately half of the three and four year olds gave wrong answers) or when the robot was facing them (approximately $30 \%$ ) gave wrong answers. Five year olds had no problem understanding the Forward switch function. The majority $(70 \%)$ of the younger participants and approximately half of the four year olds $(57 \%$ for the left turn switch and $37 \%$ for the right turn switch) were not able to correctly explain the function of the turn switches; $20 \%$ of the five year old children answered the questions regarding the turn switches incorrectly. All three year olds thought that a disconnected switch would still make the robot move, while $43 \%$ of the four year olds gave the same answer. In the five year old group the percentage of wrong answers to this question dropped to $11 \%$.

\begin{tabular}{|c|c|c|c|c|c|c|c|c|c|c|c|c|c|c|c|c|c|c|c|}
\hline \multicolumn{2}{|c|}{ Participant \# } & 8 & 12 & 9 & 16 & 7 & 6 & 14 & 10 & 17 & 3 & 15 & 5 & 13 & 20 & 11 & 4 & 18 & 19 \\
\hline \multicolumn{2}{|c|}{ Age (months) } & 35 & 35 & 36 & 38 & 38 & 46 & 47 & 47 & 48 & 49 & 49 & 51 & 52 & 62 & 63 & 63 & 63 & 63 \\
\hline \multicolumn{2}{|c|}{ Gender } & $\mathrm{M}$ & $\mathrm{M}$ & $\mathrm{F}$ & $\mathrm{F}$ & $\mathrm{M}$ & $\mathrm{F}$ & $\mathrm{M}$ & $\mathrm{M}$ & $\mathrm{M}$ & $\mathrm{F}$ & $\mathrm{F}$ & $\mathrm{M}$ & $\mathrm{M}$ & $\mathrm{M}$ & $\mathrm{F}$ & $\mathrm{F}$ & $\mathrm{M}$ & $\mathrm{F}$ \\
\hline \multirow{3}{*}{$\begin{array}{c}\text { On/Off } \\
\text { switches }\end{array}$} & Frequency & 3 & 3 & 3 & 3 & 3 & 3 & 3 & 3 & 2 & 3 & 3 & 3 & 3 & 3 & 3 & 3 & 3 & 3 \\
\hline & Skill Level & 3 & 3 & 3 & 3 & 3 & 3 & 3 & 3 & 3 & 3 & 3 & 3 & 3 & 3 & 3 & 3 & 3 & 3 \\
\hline & $\begin{array}{l}\text { Proficiency } \\
\text { measure }\end{array}$ & 3 & 3 & 3 & 3 & 3 & 3 & 3 & 3 & 2.5 & 3 & 3 & 3 & 3 & 3 & 3 & 3 & 3 & 3 \\
\hline \multirow{3}{*}{$\begin{array}{l}\text { Multi- } \\
\text { button } \\
\text { remote } \\
\text { controls }\end{array}$} & Frequency & 2 & 1 & 1 & 1 & 3 & 1 & 3 & 2 & 3 & 2 & 2 & 1 & 3 & 3 & 2 & 3 & 3 & 1 \\
\hline & Skill Level & 2 & $\mathrm{~N} / \mathrm{A}$ & $\mathrm{N} / \mathrm{A}$ & $\mathrm{N} / \mathrm{A}$ & 2 & $\mathrm{~N} / \mathrm{A}$ & 3 & 2 & 3 & 2 & 2 & $\mathrm{~N} / \mathrm{A}$ & 3 & 1 & 3 & 3 & 2 & $\mathrm{~N} / \mathrm{A}$ \\
\hline & $\begin{array}{l}\text { Proficiency } \\
\text { measure }\end{array}$ & 2 & 1 & 1 & 1 & 2.5 & 1 & 3 & 2 & 3 & 2 & 2 & 1 & 3 & 2 & 2.5 & 3 & 2.5 & 1 \\
\hline
\end{tabular}

Table 5: Technology survey results. (Frequency scores: 1 - Never, 2 - Weekly, 3 - Daily; Skill level scores: 1 -Low (trial and error), 2 -Medium, 3 - High (mastered); N/A: not applicable)

\begin{tabular}{|l|c|c|c|}
\hline $\begin{array}{l}\text { Pearson linear } \\
\text { correlation factor }\end{array}$ & Task 2 - Negation & Task 3A - Binary Logic & Task 3B - Sequencing \\
\hline $\begin{array}{l}\text { Multi-button } \\
\text { remote control } \\
\text { proficiency }\end{array}$ & 0.348 & 0.121 & 0.267 \\
\hline
\end{tabular}

Table 6: Pearson linear correlation factor between the proficiency measure in using multi-button remote controls and different task's results.

Results from the technology survey are compiled in Table 5. For each type of control a measure of proficiency was computed simply by taking the average of the scores in frequency and skill level. With this measure, a child that used one type of control weekly (score 2) with a high skill level (score 3) has the same 2.5 proficiency value as another child that uses the same type of control daily (score 3 ) but only with medium skill level (score 2). All participants used daily and mastered on/off switches but not multi-button remote controls. Correlation factors between the proficiency measure in using multi-button remote controls (see Table 5) and results for Tasks 2, 3A and $3 \mathrm{~B}$ were computed, all yielding positive values less than 0.348 (Table 6). Therefore, it can be argued that the performance in the study tasks is not linearly dependent on previous experience in using multi-button remote controls.

\section{DISCUSSION}


All participants appeared to enjoy playing with the robot. However, five among the eighteen children were shy and did not want to enter the room for the first session and the researcher had to show them the robot in the hallway to convince them. For one of the participants it was necessary to have his older sister with him for encouragement. Once she played with the robot he performed the tasks and enjoyed playing with the roverbot. Two children required prompting to touch the switch; others started hitting the available switch immediately. All but one of the participants were comfortable with the roverbot by the second session.

The results in Tables 2 and 3 show that proficiency in the tasks increases with age, as expected. All of the participants demonstrated skill in the first task, causality. Most of the participants hit the switch once to see what happened and then kept pressing it until the roverbot reached the stack of blocks and knocked it over. One participant (one of the two youngest) did not understand that holding the switch down would make the robot continue moving so she kept hitting and releasing the switch until the robot knocked over the stack of blocks (this participant hit the switch an average of 11.8 times to accomplish the task). Forman [8] found that cause and effect skills varied across three year olds, whereas Stanger and Cook [20] found that two and three year old children consistently demonstrated causality.

Negation, Task 2, had more mixed results, since this task was more difficult than causality for children aged three and four. The average number of switch hits to complete the task was always greater than one showing that every child refined the stopping position trying to get closer to the specified location at least once. Four year olds performed better than the three year olds. Five year olds completed the task in $100 \%$ of the trials. These results are consistent with Forman [8] who found that three and four year olds recognized that holding down a switch would make the robot move, but did not understand that releasing the switch (negation) is also a command (required to stop the robot), while five and six year olds had mastered this concept.

In Task 3A, binary logic, even the youngest of our participants succeeded on most trials. This is in contrast to Forman where only children older than four demonstrated the binary logic concept. However, Forman's study used one rocker switch with two directions of movement whereas this study used two separate switches for each direction located spatially on the left and right side of the forward switch. This additional spatial cue may have led to greater success. Again, five year old children succeeded in all trials.

For Task $3 \mathrm{~B}$, most of the participants understood that to knock over one of the offcentre stacks of blocks it would be necessary to use more than one switch. In general, children aged four and five years old quickly understood this requirement. However, younger children often hit the turn switch several times, making the robot turn in circles, before understanding that the forward switch had to be hit to move the robot toward the stack of blocks after the robot was properly oriented. Other participants, having hit the turn switch a second time and acknowledging the error, purposely made the robot turn 360 degrees to return to the initial position. Then, starting over, they were able to "turn first then go forward". Some of the older participants completed the task using alternative sequences of switch hits than just pressing turn and then forward. Participant \#13, aged four, used sequences of left, right and forward hits to move the robot forward to knock over the blocks. Participant \#5 knocked over the stack of blocks three times by hitting the left and right switches in sequence, causing the roverbot to move forward in a zig zag pattern. In some cases, multiple switch hits resulted from the way in which the child executed the task. Participant \#10, for example, hit the forward switch briefly in five of the trials before turning and moving forward again, 
always knocking over the desired stack of blocks. All children demonstrated some success at Task 3A. A number of children did not have any success at Task 3B. Some of the younger participants reoriented the switches so the arrow on the switch pointed in the desired direction of movement in an attempt to change the robot's direction of motion. The number of trials before success in Task 3B diminished from session 1 to session 2, showing that children hold in memory what they learned from the previous session. In Stanger and Cook's study, the three year olds could complete a two step sequence, but not three steps [20].

When the participants were asked about the functions of the switches the majority indicated that the forward switch made the robot move forward when the roverbot was pointed forward. Some of them didn't understand that if the robot is pointing left or toward the child, the same switch will move the roverbot forward relative to its orientation, i.e. towards the left or towards them. They insisted that the roverbot would move forward with respect to their own position. One child said that the robot would drive towards him but that the forward switch would have to be rotated so the arrow faced him. The participants gave several explanations for the left and right turn switch function: i) the robot turns left or turns right (the correct answer); ii) the robot goes left or right (turns and moves forward in that direction); iii) the robot goes to the position where the stack of blocks was placed (they linked the actual function of the switch with the usage they made of it). Some of the participants succeeded in Task 3B even though they could not accurately describe the function of the switches. These erroneous explanations, along with the belief of younger children that a disconnected switch will still make the robot move and that by reorienting the switch the robot would move in another direction, are consistent with the results by Forman [8], where younger children believed that the action was in the switch, not in the relationship between the switch and robot.

The absence of a high linear correlation between child's proficiency in using multibutton remote controls and their performance in Tasks 2, 3A and 3B shows that the results here presented were not biased by the children's previous experience with switches.

A limitation of the study is that the robot tasks were developed "intuitively", with the expectation that they test the cognitive skills proposed. They have not undergone construct validity testing. There are standardized tests for school age children, but they assume that fundamental skills such as these are already in place, since they usually occur before age 3 or 4 in most children. Sequencing is addressed and is a later skill closer to 4-5 years.

\section{CONCLUSIONS}

This study provides data regarding the ages at which typically developing children demonstrate understanding of causality, negation, binary logic, and sequencing while using switches to control Lego robots. These data provide a means for estimating the cognitive developmental level of children with disabilities engaged in similar robot-related tasks ... Establishing the level of understanding of these skills provides the opportunity to use the robot tasks as probes of cognitive understanding by children with disabilities. The robot task motor requirements are minimal and can be adapted to a wide range of possible anatomical control sites for activating the switch(es) (e.g., hand, head, leg, arm, etc.). There is also no need for spoken language to evaluate understanding. This is in contrast to children being underestimated due to the limitations of standardized testing procedures. One outcome that has been consistent in all of our robot studies is that teachers underestimated the abilities of the children until they saw their capabilities with the robot tasks [4].The information gathered from typically developing young children using 
robots in this study and that of Forman can assist in establishing tasks that are developmentally cognitively appropriate which provide a challenge to the children and encourage development. (e g., [6]).

The skills that were evaluated in this study have direct applicability to assistive technology use on a broad scale. Means end causality is a fundamental requirement for use of any switch activated electronic assistive device whether for simple appliance or toy activation or more complex alternative access methods to computers, environmental control units (ECU), powered mobility and augmentative and alternative communication (AAC) devices. Negation underlies the understanding that releasing a switch is an action that causes an effect. One example is inverse scanning used in AAC devices. In this mode, the cursor moves through selection elements until the switch is released at which time the selection is entered into the device [5]. This type of scanning is also used in mouse emulation for computers, menu control for ECU's as well as other electronic assistive device applications. An understanding of binary relations is necessary for driving a powered wheelchair with left and right capability. It is also important in the use of directed scanning in computers, ECU or AAC when using an on-screen keyboard. Finally, sequencing is a basic skill required in the use of computers, ECU or AAC for navigating the pages of an interface or to string together selections into meaningful commands or words.

Given the importance of these skills for effective use of assistive technologies, it is important that there be meaningful assessment of these skills in children with disabilities. For many of these children assistive technologies are being considered because of lack of speech and/or severely limited motor skillWe have identified the cognitive skills relevant to the use of assistive technology, by using robot tasks which have low motor and linguistic demands. Hence, the robot tasks could be symbol and device independent ways of looking at very specific cognitive skills without the choice of a communication element, an environmental control function or a wheelchair direction causing additional cognitive overhead. The robot tasks could provide an opportunity for children to develop skills for more sophisticated assistive technology use, for example, beyond simple cause and effect computer games.

The independence from motor or speech requirements of the robot tasks allowed us to use the tasks in a study with children who had severe disabilities and determine their levels of cognitive understanding when they were judged "untestable" by other standard measures [6]. Thus, robotic tasks such as those described in this study can be valuable in future studies as a proxy measure of disabled children's cognitive ability.

\section{REFERENCES}

[1] A. Andreopoulos and J.K. Tsotsos, A framework for door localization and door opening using a robotic wheelchair for people living with mobility impairments, Proceedings of the Robotics Science and Systems (RSS) 2007 Manipulation Workshop: Sensing and Adapting to the Real World, June 30, 2007, Atlanta.

[2] S. Besio, ed., Analysis of critical factors involved in using interactive robots for education and therapy of children with disabilities, Editrice UNI Service, Italy, 2008.

[3] A.M. Cook, P. Hoseit, M.L. Ka, R.Y. Lee, and C.M. Zenteno-Sanchez, Using a robotic arm system to facilitate learning in very young disabled children, IEEE Transactions on Biomedical Engineering 35(2) (1988), 132-7.

[4] A.M. Cook, B. Bentz, N. Harbottle, C. Lynch, and B. Miller, School-based use of a robotic 
arm system by children with disabilities, IEEE Transactions on Neural Systems and Rehabilitation Engineering 13(4) (2005), 452-460.

[5] A.M. Cook and J.M. Polgar, Cook \& Hussey's Assistive Technologies, Principles and Practice, $3^{\text {rd }}$ ed., Elsevier Inc., Philadelphia, PA, 2008.

[6] A.M. Cook, K. Adams, J. Volden, N. Harbottle, and C. Harbottle, Using Lego robots to estimate cognitive ability in children who have severe physical disabilities, Disability and Rehabilitation: Assistive Technology (in press).

[7] S.P. Eberhardt, J. Osborne, and T. Rahman, Classroom evaluation of the Arlyn Arm Robotic Workstation, Assistive Technology 12(2) (2000), 132-43.

[8] G. Forman, Observations of young children solving problems with computers and robots, Journal of Research in Childhood Education 1(2) (1986), 60-73.

[9] W.S. Harwin, A. Ginige, and R.D. Jackson, A robot workstation for use in education of the physically handicapped, IEEE Transactions on Biomedical Engineering 35(2) (1988), 127 131.

[10] R. Howell and K. Hay, Software-based access and control of robotic manipulators for severely physically disabled students, Journal of Artificial Intelligence in Education 1(1) (1989), 53-72.

[11] G. Karlan, S. Nof, N. Widmer, I. McEwen, and B. Nail, eds., Preliminary clinical evaluation of a prototype Interactive Robotic Device (IRD-1), Proceedings of the ICAART 88, 1988, Montreal, Quebec.

[12] G. Kronreif, M. Kornfeld, B. Prazak, S. Mina, and M. Fürst, Robot assistance in playful environment - user trials and results, Proceedings of the IEEE International Conference on Robotics and Automation, April 10-14, 2007, Rome, Italy.

[13] H. Kwee, J. Quaedackers, E. van de Bool, L. Theeuwen, and L. Speth, Adapting the control of the MANUS manipulator for persons with cerebral palsy: an exploratory study, Technology \& Disability 14(1) (2002), 31-42.

[14] H. Kwee, J. Quaedackers, E. van de Bool, L. Theeuwen, and L. Speth, eds., POCUS project: adapting the control of the MANUS manipulator for persons with cerebral palsy, Proceedings of the International Conference on Rehabilitation Robotics (ICORR), July 12, 1999, Palo Alto, CA.

[15] C.R. Musselwhite, Adaptive play for special needs children, College-Hill Press, San Diego, CA, 1986.

[16] S. Nof, G. Karlan, and N. Widmer, Development of a prototype Interactive Robotic Device for use by multiply handicapped children, Proceedings of the ICAART 88, 1988, Montreal, Quebec.

[17] M. Patrizia, M. Claudio, G. Leonardo, and P. Alessandro, A robotic toy for children with special needs: from requirement to design, Proceedings of the $11^{\text {th }}$ International IEEE Conference on Rehabilitation Robotics, 2009, pp. 918-923.

[18] B. Robins, E. Ferrari E, and K. Dautenhaun, Developing scenarios for robot assisted play, Proceedings of the $17^{\text {th }}$ Annual International Symposium on Robot and Human Interactive Communication, 2008, pp. 180-186.

[19] J. Smith and M. Topping, The introduction of a robotic aid to drawing into a school for physically handicapped children: a case study, British Journal of Occupational Therapy 59(12) (1996), 565-569.

[20] C.A. Stanger and A.M. Cook, Using robotics to assist in determining cognitive age of very young children, Proceedings of the IEEE Conference on Engineering in Medicine and 
Biology, 1990, pp. 1911-1912.

[21] J.K. Tsotsos, G. Verghese, S. Dickinson, M. Jenkin, A. Jepson, E. Milios, F. Nuflo, S. Stevenson, M. Black, D. Metaxas, S. Culhane, Y. Ye, and R. Mann, PLAYBOT: a visually-guided robot to assist physically disabled children in play, Image \& Vision Computing Journal, Special Issue on Vision for the Disabled, 16 (1998), 275-292.

[22] Uzgiris IC and hunt JM, Infant Performance and Experience:New Findings with the Ordinal Scales, Chicago: University of Illinois Press, 1975

[23] WHO - World Health Organization, International Classification of Functioning, Disability and Health - Children and Youth version (ICF-CY), 2007, www3.who.int/icf/onlinebrowser/-/icf.cfm? undefined\&version=7 